\title{
The Function of an Undergraduate Thesis in a Forestry Program and the Forestry Profession
}

by

Thomas G. Eiber ${ }^{1}$

The undergraduate thesis occupies an unique position in an Honour's Bachelor of Science program in that it provides the only opportunity for a student to undertake a comprehensive project dealing with a specific forestry related problem. In most cases, it requires the student to design and carry out some form of experimental research with the objective of solving a problem or at least defining and clarifing a component. In all cases, a student undertaking a thesis is required to state clearly his problem and approach, search the literature for related or relevant work, do the work, undertake the logic of a discussion, and draw a series of conclusions and recommendations. Finally, the student must prepare this information, much of which may be new to the profession and science of forestry, and write a concise and logical report. This report, or thesis, is then subject to review by his academic advisors.

This activity is rather similar to the processes and procedures followed by the student after graduation. A forester will be expected to use his knowledge and skill to solve the problems of his employer with the same ability that he exercised in the preparation of his thesis. More often than not, this report will be less formal than the thesis, but the forester will occasionally be required to prepare a more formal one outlining an entire process and procedure in logical, readable form.

The preparation of a thesis, then, should contribute substantially to the training of a forester. Firstly, he will gain new skills while undertaking a specific project and benefit from the close working liaison with a single faculty member. Secondly, he will gain the ability to think logically through a problem and perceive its solution. This is an academic exercise and certainly must be a primary goal of any university based professional training. Thirdly, the student will learn the discipline associated with independent research and thereby be a better professional. Fourthly, he will leave behind a legacy, no matter how small, of a higher state of knowledge for the faculty, future students, and the profession at large.

There are two important distinctions made between a thesis in BScF and MScF programs. The first major difference is the relative weight and importance. In the case of the BScF, it provides the student with an ability to solve problems of moderate size on a fairly independent basis. This is an opportunity not available in major laboratory exercises and the obiquitous term paper. The undergraduate thesis also carries a smaller weight relative to the rest of the program. On the other hand, the MScF thesis is much more important because of the shorter academic duration and predominant research orientation of the degree. Consequently, it also carries a much greater weight relative to the rest of the program.

The other major distinction stems directly from the first. As a Master's level thesis is intended as a research effort it must be of a quality and scope to be a valid and viable publication. The thesis at the Baccalaureate level, however, lacks some element or elements of the Master's thesis. We expect the student (and faculty) to maintain the quality and to produce the scope of the project to a level appropriate for a BScF program. As professionals, we should be able to

1'Lakehead University, Thunder Bay, ON, P7B 5E1. presume that an undergraduate thesis was well designed within the constraints of the problem and the academic program. We must not presume that an undergraduate thesis is the ultimate or final word on a subject.

Where do the six Canadian forestry schools stand with regard to a thesis requirement for the undergraduate degree? Four schools, Lakehead University, Université Laval, the University of British Columbia, and the University of New Brunswick, require an undergraduate thesis. It is optional at the University of Toronto in the Forestry program and required in the Wood Science program. The University of Alberta does not have a thesis, but has major term papers in optional courses (these are considered sufficiently rigorous by the British Columbia Professional Foresters Association that they have waived the thesis requirement for Alberta).

Table 1. Summary of thesis activities at Canadian forestry schools.

\begin{tabular}{|c|c|c|c|c|c|}
\hline School & Status & Number/yr & $\begin{array}{l}\text { Published } \\
\text { titles/year }\end{array}$ & $\begin{array}{c}\text { Collected } \\
\text { and } \\
\text { available }\end{array}$ & $\begin{array}{l}\text { Overall } \\
\text { access }\end{array}$ \\
\hline Lakehead & Required & $50-60$ & $50-60$ & All & Open \\
\hline UNB & Required & $50-60$ & $38-40$ & Selected & Open \\
\hline Laval & Required & $60-75$ & 0 & All & Limited \\
\hline $\begin{array}{l}\text { UBC } \\
\text { Toronto }\end{array}$ & Required & $45-100$ & 0 & All & Limited \\
\hline Wood Sci. & Required & 11 & 0 & None & Minimal \\
\hline Forestry & Optional & 11 & 0 & None & Minimal \\
\hline Alberta & $\begin{array}{l}\text { No } \\
\text { Thesis }\end{array}$ & 0 & - & - & - \\
\hline
\end{tabular}

In the process of preparing this article, I wrote to each school and asked a series of questions pertaining to the preparation, collection, and distribution of theses. All schools responded and the following is a general discussion of the perceptions and use of the thesis at each school, ranked by the level of access accorded to the profession at large. The data in Table 1 are a summary of their answers.

Lakehead University. Lakehead's policy is to have theses available on an open basis to all members of the student body and profession. On rare occasions, a title is limited and available only from the major advisor. All titles are published in the Forestry Chronicle (cf. Oct. 1981). Printed abstracts are bound and sent to a standard mailing list and to anyone who requests a copy of "Thesis Abstracts". Theses are loaned to members of the profession via a requesting letter or a formal interlibrary loan request. All told theses are held and continually available. Loans for the 1981 theses will approach 800 and will take over a year to process fully.

University of New Brunswick. UNB centrally collects all theses. Selected titles are published in the newsletter "UNB Forestry Focus". In a typical year about $70 \%$ of the titles are selected, but these titles are available for only one year. Older theses are only available from faculty advisors. UNB allows a jointly authored thesis to be submitted.

University of British Columbia. UBC centrally collects theses, but does not circulate their titles. They are available on a limited basis, but UBC prefers to restrict wide circulation because they are not of a MScF or PhD standard. 
Université Laval. Laval requires and centrally collects theses. They do not publish titles, but to make them available on loan through normal channels through the university library. Laval also allows 2 or 3 students to submit a "joint thesis".

University of Toronto. Toronto no longer requires a thesis in their undergraduate program in forestry, but has retained it as an option. The thesis is still a requirement in the Wood Science program. Theses numbered 11 in each program in 1981, but were not centrally collected. They may be borrowed from individual faculty members, but general access is considered minimal.

University of Alberta. Alberta does not require a thesis. The major term papers may contain an element of research, but are neither centrally collected or published and distributed.

Results of an investigation of a number of US forestry schools indicated no thesis prepared at the undergraduate level, but a number of special topic courses, usually at the senior level, which often involve the preparation of an extended term paper, are optional.

\section{Discussion}

As the six Canadian forestry schools move to meet the challenge of preparing students for forestry in the 1980's and 1990's, we will see them struggle with the need to include more and more course work in increasingly diverse subject areas. As it is fair to assume that all the programs are full with respect to course work, the inclusion of new materials will require either that students become more overloaded or that more traditional subjects are shortened or dropped altogether. I expect that the thesis may be one of those activities suggested for removal to make way for the "new", and since the thesis is a shared responsibility amongst many faculty no one's academic territory will be diminished by its deletion. Further, few faculty will fight to see the item remain which means so much work, but for which so little credit (if any) is given when workloads are calculated.

The thesis should be retained as a part of the curriculum in our forestry schools! In a time of liberalization of programs it is the only activity sufficiently flexible to serve any subject area (cf. the Lakehead listing in the October, 1981 Forestry Chronicle or the UNB Forestry Focus). The thesis also teaches the student to think and work independently to achieve the solution of a problem. The profession continues to borrow theses at an increasing rate and many people are repeat borrowers. Senior students are often sought after by employers with potential projects in hand. It seems the profession at large recognizes the usefulness of the undergraduate thesis, and we ignore it at our own peril.

Perhaps the analogy that a BScF thesis is a single brick, a MScF thesis is a wall, and a PhD thesis is a house is appropriate. I should think that we need and can use all three in the profession. I hope you agree.

\title{
The Six Canadian Forestry Schools: A Status Report
}

\author{
by
}

\author{
A.J. Kayll ${ }^{1}$
}

Recent forecasts of needs for practising professional foresters and specialists (Beltzner 1981, Nordin 1981, Place 1981) place requirements in the order of seven to eight thousand in the current decade, with the greatest demand coming after 1985. Hart (1981), Harding (1981) and Reed (1981) support the forecasts, but even if you discount the numbers $25 \%$, the six Forestry Schools in Canada will fall far short because of their limited physical, financial and human resources.

The numbers of students the Schools graduated in 1981, and expect to graduate in 1982 and 1983, are given in Tables 1 and 2. The average is about 466 per year, or a short-fall of 20 to $40 \%$ of forecasted demand for the 1981-90 decade, depending on which forecast you prefer. It has been argued that the intensity of practice in the managed forests of the ' 80 's will not be uniform, and, therefore, it is inappropriate to apply the forecasts uniformly across the country. While this is true, graduates are also not uniformly distributed: of the 333 bachelor level 1981 graduates, $28 \%$ (92) graduated from Laval and will likely stay in the Province of Quebec. Shortages in other parts of Canada may be worsened, but the current apparent surplus in Quebec may have contributed to the low first year enrolment (incidentally, these students will be graduating when demand is forecasted to peak).

If it is argued that the Schools should produce more

\footnotetext{
${ }^{1}$ Secretary-Treasurer, Association of University Forestry Schools of Canada/l'Association
} des Ecoles forestières universitaires du Canada.
Table 1. Students graduating from Canadian forestry schools. 1

\begin{tabular}{llccccc}
\hline & BScF & BScFE & Sub-Total & MF/MScF & PhD & Total \\
\hline 1981 & 325 & 8 & 333 & 59 & 21 & 413 \\
1982 & 378 & 15 & 393 & $90^{2}$ & $20^{3}$ & 503 \\
1983 & $347^{4}$ & $23^{4}$ & 373 & $90^{2}$ & $20^{3}$ & 483 \\
\hline
\end{tabular}

${ }^{1}$ Based in part on data collected under the auspices of the Corporate Planning Group. Policy Directorate, Environment Canada. Interpretations are those of the author.

2 Assumes a 2-year program with one-half graduating each year:

3 Assumes one-third graduating each year.

${ }^{3}$ Assumes one-third graduating each year.
${ }^{4}$ Assumes $10 \%$ attrition of current penultimate year students.

foresters, then it must be put in context. The Schools, in terms of enrolments vs. current constrained budgets, physical facilities, and constraints on filling vacant faculty positions, are all working at or near full capacity. Applying an ideal student/faculty ratio of $12.5 / 1$ to the national total of 168 faculty produces 2087 students. There are currently 2248 in the system (including 246 graduate students) giving a ratio of 13.4 even if graduate students are excluded, Lakehead has the highest ratio (20.7/1). It would like to achieve $15 / 1$ and concomitantly enhance its graduate program. Alberta has the lowest undergraduate student ratio (7/1), but has an active graduate program, and some faculty are also involved in other programs.

Data presented in Table 2 illustrate how four of the Schools are remarkably similar in terms of full-time academic and support staff, and how Laval and British Columbia are equally similar. But in terms of undergraduate 